удК 347.157

В. В. Скоробогатова

Восточно-Сибирский Институт Министерства внутренних дел Российской Федерации, г. Иркутск, Российская Федерация

\title{
ПРИЗНАНИЕ НЕДЕЕСПОСОБНЫМ ИЛИ ОГРАНИЧЕННО ДЕЕСПОСОБНЫМ НЕСОВЕРШЕННОЛЕТНЕГО ЛИЦА: СРАВНИТЕЛЬНО-ПРАВОВОЙ АСПЕКТ
}

\begin{abstract}
АНнотАцИЯ. Статья посвящена анализу норм российского и иностранного гражданского права, регулирующих дееспособность несовершеннолетних лиц, сделан вывод о возможности признания недееспособным несовершеннолетнего лица, достигшего возраста 14 лет, определено, что нормы об ограничении дееспособности в связи со злоупотреблением спиртными напитками, наркотическими веществами и пристрастия к азартным играм не целесообразно применять к несовершеннолетним лицам. Дана характеристика основаниям и последствиям признания гражданина недееспособным и ограниченно дееспособным, акцентировано внимание на различиях в способностях субъекта, обладающего не полным объемом дееспособности в силу несовершеннолетнего возраста и по иным причинам, таким как психическое состояние, обладание различного рода зависимостями. Выявлены сходства и различия между нормами российского, французского и германского права, регулирующих дееспособность несовершеннолетних лиц. Российское гражданское законодательство обладает характерными отличительными чертами в части определения объема дееспособности несовершеннолетних, позволяющими признавать недееспособными несовершеннолетних лиц, достигших возраста 14 лет, что направлено на дополнительную защиту их прав и интересов.

кЛючЕВЫЕ словА. Несовершеннолетние; признание ограниченно дееспособным; признание недееспособным; группы дееспособности; дееспособность несовершеннолетних; виды оснований ограничения дееспособности.

ИНФОРМАЦИЯ О СТАТЬЕ. Дата поступления 5 июля 2017 г.; дата принятия к печати 19 декабря 2017 г.; дата онлайн-размещения 29 декабря 2017 г.
\end{abstract}

V. V. Skorobogatova East-Siberian Institute of the Ministry of Internal Affairs, Irkutsk, Russian Federation

\section{RECOGNITION OF A MINOR AS BEING INCOMPETENT OR PARTIALLY INCOMPETENT: COMPARATIVE-LEGAL ASPECT}

\begin{abstract}
The article is devoted to analyzing the norms of the Russian and the foreign civil laws that regulate the competence of the minors; it makes conclusion on a possibility of a minor, who has reached the age of 14 , to be recognized as incompetent. The article specifies that it is not advisable to apply to the minors the norms on special disability in relation to overuse of alcohol, drugs and gambling addiction. It characterizes the basics and consequences of admitting a citizen as incompetent and partially incapacitated, focuses attention on differences in abilities of the subject who does not have the full capacity due to the minority and for other reasons, such as mental state, possession of various kinds of dependencies. The article reveals the similarities and differences between the norms of Russian, French and German laws regulating the legal capacity of the minors. The Russian civil legislation has distinctive features in terms of determining the capacity amount of the minors that allow to recognize the minors who have reached the age of 14 to be incompetent, which is aimed at additional protection of their rights and interests.

KEYWORDS. Minors; admission of partial incompetence; admission of incompetence; group capacity; legal capacity of minors; types of grounds for capacity limitations.
\end{abstract}

(C) В. В. Скоробогатова, 2017

\section{Baikal Research Journal}


ARTICLE INFO. Received July 5, 2017; accepted December 19, 2017; available online December 29, 2017.

Институт признания гражданина недееспособным и ограниченно дееспособным известен практически всем правовым системам. Очевидно, что вступать в правоотношения и совершать юридически значимые действия может только волеспособный субъект при этом любой дефект волеспособности не может быть безразличен праву. Дееспособность гражданина зависит от волеспособности, волеспособность, в свою очередь, предполагает определенный уровень психической зрелости. Уровень психической зрелости можно определить несколькими способами: применительно к каждому конкретному субъекту, учитывая различные факторы, влияющие на его развитие, либо моментом достижения определенного возраста.

В свое время, С. И. Архипов предложил несколько критериев дееспособности: условия, характеризующие готовность субъекта права с точки зрения его воли, способность принимать правовые решения; организационные условия; условия, характеризующие имущественное положение лица; условия, характеризующие возможности правового взаимодействия лица, его участия в правовых связях, отношениях (коммуникативно-правовые условия); функциональные возможности (качества, способности) правового лица; поведенческие условия [1, с. 26.].

Все перечисленные критерии, безусловно, влияют на дееспособность субъекта, однако, определять момент возникновения полной дееспособности наличием или отсутствием подобных критериев не представляется целесообразным. Потому как, наличие или отсутствие данных критериев необходимо будет рассматривать применительно к каждой личности отдельно и принять решение о полной дееспособности лица сможет только суд, это невероятно затруднит гражданский оборот, кроме того подобный процесс будет существовать не в пользу защиты прав и законных интересов субъекта. Практически во всех государствах момент возникновения полной дееспособности установлен достижением определенного возраста, как правило, 18 летнего (Россия в данном случае не является исключением). Законодатель устанавливает тем самым «презумпцию дееспособности», предполагая, что любой субъект, достигший 18 лет, достигает необходимого уровня психической зрелости и становится полностью дееспособным [2, с. 213].

В то же время, уровень развития волеспособности зависит не только и не столько от возраста, сколько от определенного набора социальных, психологических, психофизических, коммуникативных и т.п. качеств, которые субъект как раз и приобретает, достигнув определенного возраста. Нельзя исключать и особенности в развитии каждой личности, а также тот набор качеств, которые были выделены Архиповым С. И., они также влияют на дееспособность субъекта, и они тем или иным образом учитываются правом, определяющим дееспособность субъекта.

Несмотря на то что полностью дееспособным считается лицо, достигшее 18 лет, в то же время с точки зрения права, помимо возраста, на дееспособность влияет психическое и психологическое состояние лица. Например, признать гражданина недееспособным возможно в том случае, если он в следствии психического расстройства не может понимать значения своих действий или руководить ими, а ограничить дееспособность суд может, если гражданин в следствии злоупотребления спиртными напитками ставит свою семью в тяжелое материальное положение.

Вполне прогнозируется ситуация, при которой возможно возникновение одновременно несколько факторов определяющих дееспособность: несовершеннолетний возраст и психическое расстройство, влияющее на способность понимать значение своих действий или руководить ими, либо несовершеннолетний возраст и злоупотребление наркотическими средствами, в результате которого он ставит

\section{Baikal Research Journal}

электронный научный журнал Байкальского государственного университета 
свою семью в тяжелое материальное положение. Какой из критериев для определения дееспособности следует выбрать в подобных случаях, вопрос не праздный и ответ на него не так очевиден, как кажется на первый взгляд.

Предпримем попытки найти решение подобной проблемы, обратившись к нормам российского и иностранного законодательства, регулирующего вопросы дееспособности физических лиц. Следует различать группы граждан по дееспособности, критериями такого разграничения является возраст, психическое состояние лица и т.д.

Обратимся к нормам российского гражданского права.

Физические лица по признаку волеспособности делятся на несколько групп: недееспособные, частично дееспособные, относительно дееспособные, ограниченно дееспособные и дееспособные. В соответствие с общим правилом российского современного законодательства полной дееспособностью обладает лицо, достигшее 18 лет, конечно из этого правила есть исключения, зависящие от особенностей отрасли права.

По возрастному критерию лица подразделяются на малолетних в возрасте до 6 лет, которые являются недееспособными; несовершеннолетних в возрасте от 6 до 14 лет, которых принято называть частично дееспособными; и несовершеннолетних в возрасте от 14 до 18 лет, являющихся относительно дееспособными [3, c. 25]. С точки зрения права к недееспособным и ограниченно дееспособным относятся лица, признанные таковыми по решению суда в результате наличия у них различных психических заболеваний, зависимостей, которые оказывают влияние на их волеспособность и как следствие этому на способность совершать юридически значимые действия.

Традиционно для российского законодательства, нормы о признании гражданина недееспособным и ограниченно дееспособным содержатся в Гражданском кодексе РФ ${ }^{1}$. Субъект, ограничивается, как правило, в гражданской дееспособности, при этом объем дееспособности в других отраслях права остается неизменным. Признание гражданина недееспособным, имеет межотраслевое значение, т.е. субъект, признанный недееспособным, недееспособен с точки зрения всех отраслей права.

Основания ограничения дееспособности содержатся в ст. 30 ГК РФ, к ним относятся: пристрастие к азартным играм, злоупотребление спиртными напитками или наркотическими средствами, в результате которых гражданин ставит свою семью в тяжелое материальное положение; психическое расстройство, в результате которого гражданин может понимать значение своих действий или руководить ими лишь при помощи других лиц. Признают недееспособным лицо, страдающее психическим расстройством, в результате которого оно не может понимать значения своих действий или руководить ими (ст. 29 ГК РФ). Решение об ограничении дееспособности или признании недееспособным принимает суд.

Большинству современных правовых систем различных государств известен институт признания гражданина недееспособным и ограничения дееспособности. Основаниями для принятия подобного решения обычно являются состояния психического здоровья, физические недуги, различные зависимости. Нормы таких институтов реализуются чаще всего в судебном порядке, что говорит о значимости волеспособности субъекта для его участия в правоотношениях.

Французское гражданское право предусматривает возможность признания недееспособным или ограниченно дееспособным совершеннолетнего лица, основанием для этого являются слабоумие, душевная болезнь, расточительство, фи-

${ }^{1}$ Гражданский кодекс Российской Федерации (часть первая) : федер закон от 30 нояб. 1994 г. № 51-ФЗ : (ред. от 28 марта 2017) // Собрание законодательства РФ. 1994. № 32. Ст. 3301.

\section{Baikal Research Journal}

электронный научный журнал Байкальского государственного университета 
зические недостатки - глухота, слепота $[4$, с. 156]. В Германии уделяя большое внимание социальным проблемам алкоголизма и наркомании, предусмотрели номы об ограничении дееспособности по таким основаниям как злоупотребление спиртными напитками и наркотическими веществами [5, с. 91]. Следует отметить, что одного лишь злоупотребления не достаточно для ограничения дееспособности, необходимо, чтобы лицо ставило себя и свою семью в состояние крайней нужды и не могло заботиться о своих делах. Над лицом, признанным недееспособным или ограниченным в дееспособности устанавливается опека, в Великобритании и США института опеки не существует, этот пробел восполняется институтом доверительной собственности, который называется trast (буквально - доверие) [6, с. 403]. Институт траста не известен континентальному праву, если говорить о России, то в нашем гражданском законодательстве существует договор доверительного управления имуществом, но эти отношения носят характер обязательственных, тогда как в Великобритании и США траст - это вещные правоотношения [7, с. 106].

Объем дееспособности несовершеннолетних в разных странах не одинаков, они могут быть либо полностью недееспособными либо обладать ограниченным объемом дееспособности. Во Франции лицо до достижения 18 лет считается недееспособным, имуществом несовершеннолетнего управляют родители или опекуны, но по достижении 16 лет они могут совершать ряд сделок, не являющихся убыточными и не нарушающими их прав, с согласия родителей $[8$, с. 80]. В Германии ребенок до 7 лет абсолютно недееспособен, с 7 до 18 лет - ограниченно дееспособен и может совершать некоторые сделки с согласия родителей, а также самостоятельно вправе совершать сделки, приносящие правовую выгоду, сделки в пределах суммы на "карманные расходы», сделки, совершаемые при ведении предпринимательской деятельности, если получил на это согласие законных представителей, также вправе заключать договор трудового найма и все сделки, которые связаны с исполнением этого договора [6, с. 315]. В Великобритании несовершеннолетний в возрасте до 18 лет является ограниченно дееспособным, дееспособность несовершеннолетних регулируется на основе судебных прецедентов. В соответствие со сложившейся практикой сделки, совершаемые несовершеннолетними, делятся на четыре группы: действительные сделки; оспоримые сделки; безусловно, недействительные сделки; договоры, связывающие несовершеннолетнего только по их прямому подтверждению по достижению совершеннолетия. Кроме того, дееспособность несовершеннолетнего, достигшего 16 лет, может быть восполнена с помощью эмансипации, в результате которой несовершеннолетний по решению суда может быть признан полностью дееспособным [6, с. 421].

Как нами было определено ранее в соответствии с ГК РФ несовершеннолетние по дееспособности подразделяются на несколько групп. Вопрос о возможности применения к несовершеннолетним норм о признании лица недееспособным или ограниченно дееспособным остается открытым. Несовершеннолетние итак не обладают полной дееспособностью в силу того, что не достигли совершеннолетия (18 лет), насколько будет достаточно существующих возрастных ограничений дееспособности и не возникнет ли необходимость применять и другие основания, влияющие на объем дееспособности. Для того чтобы ответить на этот вопрос, необходимо рассмотреть суть оснований признания лица недееспособным или ограниченно дееспособным и последствий принятия подобного решения.

Исходя из буквального толкования правила ст. 22 ГК РФ дееспособность гражданина может быть ограничена только в случаях, установленных законом.

Основания ограничения дееспособности гражданина можно классифицировать в зависимости от целей, на которые они направлены, на три группы [9, с. 12]:

\section{Baikal Research Journal}

электронный научный журнал Байкальского государственного университета 
1. Ограничение дееспособности с целью охраны имущественных прав и интересов других лиц - если субъект, ограничиваемый в дееспособности, совершает какие-то действия, затрагивающие права и охраняемые законом интересы других лиц;

2. Ограничение дееспособности с целью охраны имущественных прав и интересов субъекта, ограничиваемого в дееспособности - в случае, совершения им неразумных действий, затрагивающих его права и охраняемые законом интересы;

3. Ограничение дееспособности с целью охраны имущественных прав и интересов субъекта, ограничиваемого в дееспособности, а также прав и интересов других лиц при применении процедур банкротства (гражданина, обладающего статусом индивидуального предпринимателя, или гражданина, не обладающего таким статусом).

Ко второй группе оснований ограничения дееспособности можно отнести правило п. 4 ст. 26 ГК РФ, в силу которого несовершеннолетнего в возрасте от 14 до 18 лет при наличии достаточных к тому причин ограничиваются в праве самостоятельно распоряжаться своими заработком, стипендией или иными доходами. В том случае если несовершеннолетние не могут правильно и разумно распорядиться своими доходами, по инициативе законного представителя может быть ограничена свобода несовершеннолетнего по распоряжению денежными средствами, законные представители обязаны распоряжаться доходами несовершеннолетнего только в его интересах.

Как было отмечено выше, иностранному законодательству также известно правило об ограничении дееспособности, в силу которого ограничивается самостоятельность несовершеннолетнего в распоряжении своими доходами (например, $\S 107-111$ ГГУ) [5, с. 568].

Однако и российским правом, и правом иностранных государств возможность признания недееспособным или ограничения и дееспособности в силу злоупотребления спиртными напитками, азартными играми, расточительства и психического расстройства предусмотрена в отношении полностью дееспособного гражданина. Например, в § 1896 ГГУ прямо говорится, что суд может назначить попечителя совершеннолетнем лицу, которое вследствие психической болезни, телесных повреждений, умственного или психического расстройства не в состоянии полностью или частично вести свои дела [5, с. 566]. Подобное правило содержится и во Французском гражданском кодексе [10, с. 82]: совершеннолетний, который вследствие расстройства психического состояния не может самостоятельно заботиться о своих интересах, защищается законом либо в отношении отдельного действия, либо постоянным образом. Кроме того, в дееспособности может быть ограничен совершеннолетний, который в результате своего расточительства или праздности рискует впасть в нищету либо ставит под угрозу исполнение своих семейных обязанностей.

В то же время, правила ст.ст. 29 и 30 ГК РФ прямо не закрепляют, что применяются только к полностью дееспособным лицам.

В литературе не раз высказывались мнения о том, что по основаниям ст. 30 ГК РФ ограничить в дееспособности и признать недееспособным можно не только полностью дееспособного, но и несовершеннолетнего гражданина [3, с. 12].

Бесспорно утверждение о том, что лишить или ограничить можно только того, чем субъект обладает в полной мере [11, с. 27]. Несовершеннолетние либо недееспособны совсем, либо обладают частичной или относительной дееспособностью, поэтому ограничить в дееспособности или признать недееспособными их можно только в той части дееспособности, которой они обладают.

Последствия признания лица недееспособным или ограниченно дееспособным и последствия обладания не полным объемом дееспособности несовершеннолетними отличаются.

\section{Baikal Research Journal}

электронный научный журнал Байкальского государственного университета 
Малолетние в возрасте до 6 лет - недееспособны, следовательно, все юридически значимые действия за них и в их интересах совершают опекуны. Объем дееспособности несовершеннолетних в возрасте от 6 до 14 лет позволяет им самостоятельно совершать мелкие бытовые сделки, сделки, направленные на безвозмездное получение выгоды, сделки по распоряжению средствами, предоставленными законными представителями или с их согласия третьим лицом. В то же время ответственность и по совершенным сделкам и за причиненный вред несут родители. Несовершеннолетние в возрасте от 14 до 18 лет обладают достаточно большим объемом дееспособности и способны самостоятельно совершать сделки, которые могут совершать малолетние в возрасте от 6 до 14 лет, а также способны самостоятельно распоряжаться своим заработком и иными доходами, осуществлять права автора, вносить вклады в кредитные организации и распоряжаться ими, по достижении 16 лет вправе быть членами кооперативов. Кроме того, несовершеннолетние в возрасте от 14 до 18 лет несут имущественную ответственность по сделкам, совершенным ими самостоятельно, а также самостоятельно возмещают причиненный ими вред.

Все сделки от имени лица, признанного недееспособным, совершает его опекун, вред причиненный лицом, признанным недееспособным, также возмещает его опекун. Лицо, ограниченное в дееспособности по основаниям злоупотребления спиртными напитками и наркотическими веществами, пристрастия к азартным играм, может самостоятельно совершать мелкие бытовые сделки, все остальные сделки он совершает только с согласия попечителя, однако имущественную ответственность по совершенным сделкам и причиненный вред он несет самостоятельно. Лицо, ограниченное в дееспособности по основаниям наличия психического расстройства в результате которого он может понимать значение своих действии или руководить ими только при помощи других лиц, может распоряжаться своими доходами в виде социальных выплат, алиментов только с письменного согласия попечителя, такой гражданин самостоятельно несет ответственность по совершенным им сделкам и за причиненный вред.

Уровень юридически значимой волеспособности малолетних в возрасте до 14 лет достаточно низок и большинство их прав осуществляется законными представителями, а вот уровень волеспособности подростков от 14 до 18 лет значительно выше и их имущественная (и не только) самостоятельность может принести существенный ущерб их же интересам в том случае, если наличиствуют пороки воли и волеизъявления, связанные с психическими заболеваниями, различного рода злоупотреблениями и т.п. Поэтому, мнение о том, что ограничить в дееспособности или признать недееспособным, в том числе, и несовершеннолетних, оправданно только в отношении несовершеннолетних достигших 14 лет.

Следует обратить внимание, что судебная практика идет именно по такому пути, когда речь идет о признании гражданина полностью недееспособным. В частности, Обзор законодательства и судебной практики Верховного Суда РФ за четвертый квартал 2005 г. (утв. Постановлением Президиума Верховного Суда РФ от 1 марта 2006 г.), дает однозначный ответ, что несовершеннолетний в возрасте от 14 до 18 лет может быть признан судом недееспособным в том объеме дееспособности, которым он наделен в соответствии со ст. 26 ГК РФ².

$\mathrm{C}$ одной стороны, нельзя лишить того, чем субъект не обладает, с другой стороны, несовершеннолетние в возрасте от 14 до 18 лет относительно дееспособны и они могут самостоятельно совершать ряд сделок, направленных, например, на отчуждение или приобретение имущества. При таком положении дел, если несовер-

${ }^{2}$ Бюллетень Верховного Суда РФ. 2006. № 5 ; Бюллетень Верховного Суда РФ. 2008. № 5.

\section{Baikal Research Journal}

электронный научный журнал Байкальского государственного университета 
шеннолетний не может понимать значения своих действий или руководить ими, то вред, приносимый им от самостоятельного совершения подобных действий, вполне прогнозируем. В том случае, если не допускать возможности признавать подобных лиц недееспособными, то у родителей не будет механизма, с помощью которого они могли бы защитить права своего ребенка (а именно на защиту прав недееспособного, в первую очередь, направлены нормы ст. 29 ГК РФ). Кроме того, еще раз обратим внимание, что в ст. 29 ГК РФ прямо не указано, что недееспособным можно признать только совершеннолетнего полностью дееспособного гражданина.

Анализ, например, германских и французских норм о дееспособности дает возможность сделать вывод о том, что, во-первых, они позволяют ограничить в дееспособности по основаниям злоупотребления спиртными напитками, наркотическими веществами, азартными играми, расточительства и психического расстройства или признать недееспособным только совершеннолетнее лицо, во-вторых, французское право различает основании и последствия признания недееспособным и ограничения дееспособности, а германское право - нет.

Российское право различает основания и последствия ограничения дееспособности и признания недееспособным. Как мы уже определили ранее, в ГК РФ, в отличие от ГГУ и ФГК, нет прямого указания на то, что ограничить дееспособность и признать недееспособным можно только совершеннолетнее лицо, но возможность признать недееспособным несовершеннолетнего в возрасте от 14 до 18 лет предусматривает сложившаяся судебная практика. Тогда как, ограничить дееспособность несовершеннолетнего в силу оснований ст. 30 ГК РФ нельзя, хотя правило ст. 30 ГК РФ сформулировано также как и ст. 29 ГК РФ: «Гражданин, который вследствие...».

На наш взгляд, однозначно ответить на вопрос о возможности и, главное, необходимости ограничения дееспособности несовершеннолетнего по основаниям ст. 30 ГК РФ очень трудно. Поиск ответа на этот вопрос неизменно порождает другой, вопрос о цели ограничения дееспособности гражданина. Ранее приведена классификация оснований ограничения дееспособности в зависимости от целей, на которые они направлены. Если следовать данной классификации, то целью оснований ограничения дееспособности п. 1 ст. 30 ГК РФ является в первую очередь защита прав и интересов других лиц, потому что присутствует обязательное условие: «ставит свою семью в тяжелое материальное положение», а также последствия: он вправе самостоятельно совершать только мелкие бытовые сделки, совершать иные сделки только с согласия попечителя, попечитель получает и расходует заработок, пенсию и иные доходы подопечного в интересах подопечного, ограниченно дееспособный самостоятельно несет имущественную ответственность по совершенным им сделкам и за причиненный им вред. При таких условиях применять правило п. 1 ст. 30 ГК РФ к несовершеннолетним бессмысленно, потому что подобные последствия вполне можно получить в рамках ст. 26 ГК РФ. Целью п. 2 ст. 30 ГК РФ является защита интересов субъекта, ограничиваемого в дееспособности, именно такую цель преследует и п. 4 ст. 26 ГК РФ, и если основания ограничения дееспособности будут отличаться, то последствия вполне совпадут, что также делает нецелесообразным применения правила п. 2 ст. 30 ГК к несовершеннолетним, в возрасте от 14 до 18 лет.

Цели и последствия различного объема дееспособности зависят от основания наделения субъекта тем или иным объемом дееспособности или признания его недееспособным. Цели и последствия, несомненно, различаются, как и основания. Определим, как повлияет на объем несовершеннолетнего лица признание его недееспособным. Во-первых, несовершеннолетний, признанный недееспособным, не будет способен самостоятельно совершать тот ряд сделок, которые пред-

\section{Baikal Research Journal}

электронный научный журнал Байкальского государственного университета 
усмотрены ст. 26 ГК РФ, во-вторых, он не понесет самостоятельной ответственности за причиненный вред. Таким образом, несовершеннолетний, признанный недееспособным, не совершит юридически значимых действий в ущерб своим интересам, не попадет в руки мошенников. В-третьих, такие субъекты получают определенные социальную защиту, в том числе и материального характера, что во многих случаях является необходимым для достойного существования, а также для получения необходимой медицинской помощи. Недееспособные лица находятся под дополнительной охраной и защитой государства, особенно это важно в случае смерти опекуна. Полагаем, что на несовершеннолетних лиц в возрасте от 14 до 18 лет распространяются нормы о признании гражданина недееспособным.

Институт признания лица недееспособным и ограниченно дееспособным в России имеет свои особенности в порядке закрепления и применения норм. Германское и Французское законодательство позволяет признать недееспособным только совершеннолетнее лицо, ограничить в дееспособности по основаниям злоупотребления спиртными напитками, наркотическими веществами, азартными играми, расточительства и психического расстройства также возможно только совершеннолетнее лицо. Французское право в отличие от германского, различает основания и последствия признания недееспособным и ограничения дееспособности. Германское законодательство, в свою очередь предусматривает ограничение дееспособности несовершеннолетнего в силу которого ограничивается его самостоятельность в распоряжении своими доходами.

Российское право различает основания и последствия признания недееспособным и ограничения дееспособности гражданина. Гражданский кодекс РФ не предусматривает отдельных правил для признания недееспособным или ограничения дееспособности несовершеннолетних, не запрещая при этом применять к ним общие положения о признании недееспособным или ограничении дееспособности. Нормы ст. ст. 29 и 30 ГК РФ не содержат указаний на то, что применяются только в отношении совершеннолетних или полностью дееспособных лиц.

Толкование правила ст. 29 ГК РФ позволяет признать недееспособным несовершеннолетнее лицо, по такому пути идет и судебная практика.

Основания ограничения дееспособности подразделяются на несколько видов в зависимости от целей. В соответствие со ст. 26 ГК РФ несовершеннолетнего в возрасте от 14 до 18 лет при наличии достаточных причин можно ограничить в праве самостоятельно распоряжаться своим заработком, стипендией или иными доходами, что является одним из оснований ограничения дееспособности. Ограничивать несовершеннолетнего в дееспособности по правилам ст. 30 ГК РФ представляется нецелесообразным, потому как, несмотря на различия оснований, совпадают цели ограничения дееспособности по правилам ст. ст. 30 и 26 ГК РФ - защита прав и интересов других лиц, либо защита прав и интересов лица, ограничиваемого в дееспособности.

Сравнительный анализ гражданского законодательства нескольких государств, регулирующего дееспособность физических лиц, в том числе и несовершеннолетних, показал наличие множества схожих черт при существовании все же некоторых различий, Российское гражданское право обладает некоторыми особенностями, позволяющими признать недееспособным несовершеннолетнее лицо, которые, на наш взгляд, направлены на дополнительную защиту прав и интересов лиц и не нуждаются в корректировке или попытках перенять зарубежный опыт именно в этой части.

\section{Baikal Research Journal}

электронный научный журнал Байкальского государственного университета 


\section{Список использованной литературы}

1. Архипов С. И. Субъект права (теоретическое исследование) : автореф. дис. ... д-ра. юрид. наук : 12.00.01 / С. И. Архипов. - Екатеринбург, 2005. - 31 с.

2. Матузов Н. И. Теория государства и права : учебник / Н. И. Матузов, А. В. Малько. - М. : Юрист, 2004. -245 с.

3. Сухарева Е. Р. Гражданско-правовая дееспособность и деликтоспособность малолетних и несовершеннолетних / Е. Р. Сухарева // Вестник Воронежского института МВД России. - 2016. - № 1. - С. 178-185.

4. Гражданское и торговое право капиталистических государств : учебник / ред. Е. А. Васильев. - 3-е изд., перераб. и доп. - М. : Междунар. отношения, 1993. - 560 с.

5. Гражданское уложение Германии. Вводный закон к Гражданскому уложению : пер. с нем / ред. В. Бергман. - 3-е изд., перераб. - М. : Волтерс Клувер, 2008. — 896 с.

6. Хрестоматия по истории государства и права зарубежных стран. Новое и Новейшее время / сост. Н. А. Крашенинников. - М. : ЗЕРЦАЛО, 1999. - 850 с.

7. Крашенинников П. В. Зарождение права / П. В. Крашенинников. - М. : Статут, 2016. - 342 c.

8. Михеева Л. Ю. Основания и последствия установления опеки над недееспособными гражданами / Л. Ю. Михеева // Современное право. - 2001. - № 11. - С. 12-16.

9. Скоробогатова В. В. Правосубъектность граждан в российском гражданском праве : автореф. дис. ... канд. юрид. наук : 12.00.03 / В. В. Скоробогатова. - Екатеринбург, 2010. $-25 \mathrm{c}$.

10. Маковская А. А. Реформа договорного права во Франции. Новые положения Гражданского кодекса Франции / А. А. Маковская. // Вестник экономического правосудия Российской Федерации. - 2016. - № 8. - С. 76-101.

11. Минникес И. А. Субъект ответственности: проблемы правосубъектности / И. А. Минникес, В. В. Скоробогатова, С. М. Белозерцев // Вестник Восточно-Сибирского института МВД России. - 2016. - № 4 (79). - С. 63-67.

\section{References}

1. Arkhipov S. I. Sub"ekt prava (teoreticheskoe issledovanie). Aftoref. Dr. Diss. [Subject of law (theoretical research). Dr. Diss. Thesis] Ekaterinburg, 2005. 31 p.

2. Matuzov N. I., Mal'ko A. V. Teoriya gosudarstva i prava [Theory of State and Law]. Moscow, Yurist Publ., 2004. 245 p.

3. Sukhareva E. R. Civil Law Active and Delictual Dispositive Capacity of Minors and Juveniles. Vestnik Voronezhskogo instituta MVD Rossii = The bulletin of Voronezh Institute of the Ministry of Internal Affairs of Russia. 2016, no. 1, pp. 178-185. (In Russian).

4. Vasil'ev E. A. (ed.) Grazhdanskoe i torgovoe pravo kapitalisticheskikh gosudarstv [Civil and trade law of capitalist states]. $3^{\text {th }}$ ed. Moscow, Mezhdunarodnye otnosheniya Publ., 1993. $560 \mathrm{p}$.

5. Fahse H., Hadding W., Heinrich I.,| Herzler F. (eds). Burgerliches Gesetzbuch mit Einfuhrungsgesetz und Nebengesetzen. 12 Aufl. Berlin, Kohlhammer, 2002. 760 s. (Russ. ed.: Bergman V. (ed.). Grazhdanskoe ulozhenie Germanii. Vvodnyi zakon $k$ Grazhdanskomu ulozheniyu. Moscow, Volters Kluver Publ., 2008. 896 p.).

6. N. A. Krasheninnikov (ed.). Khrestomatiya po istorii gosudarstva i prava zarubezhnykh stran. Novoe i Noveishee vremya [Chrestomathy on history of government and law in foreign countries]. Moscow, Zertsalo Publ., 1999. 850 p.

7. Krasheninnikov P. V. Zarozhdenie prava [Origin of Law]. Moscow, Statut, 2016. 342 p.

8. Mikheeva L. Yu. Grounds and consequences of setting the custody of incompetent citizens. Sovremennoe pravo = Modern law, 2001, no. 11, pp. 12-16. (In Russian).

9. Skorobogatova V. V. Pravosub"ektnost' grazhdan v rossiiskom grazh-danskom prave. Aftoref. Kand. Diss. [Legal personality of citizens in the Russian civil law. Cand. Diss. Thesis]. Ekaterinburg, 2010. 25 p.

10. Makovskaya A. Reform of Contract Law in France. New Provisions of the French Civil Code. Vestnik ekonomicheskogo pravosudiya Rossiiskoi Federatsii = Bulletin of Economic Justice of the Russian Federation. 2016, no. 8, pp. 76-101. (In Russian).

\section{Baikal Research Journal}


11. Minnikes I. A., Skorobogatova V. V., Belozertsev S. M. The Subject of Responsibility: Legal Problems. Vestnik Vostochno-Sibirskogo instituta MVD Rossii = Vestnik Eastern Siberia Institute of the Ministry of the Interior of the Russian Federation, 2016, no. 4 (79), pp. 63-67. (In Russian).

\section{Информация об авторе}

Скоробогатова Виктория Владимировна - кандидат юридических наук, доцент, кафедра гражданско-правовых дисциплин, Восточно-Сибирский Институт Министерства внутренних дел Российской Федерации, г. Иркутск, ул. Лермонтова, 110, 664074, e-mail: sarrav@mail.ru.

\section{Author}

Victoria V. Skorobogatova - PhD in Law, Associate Professor, Chair of Civil and Law Sciences, Eastern Siberian Institute of the Ministry of Internal Affairs, 110 Lermontov St., 664074, Irkutsk; e-mail: sarrav@mail.ru.

\section{Для цитирования}

Скоробогатова В. В. Признание недееспособным или ограниченно дееспособным несовершеннолетнего лица: сравнительно-правовой аспект / В. В. Скоробогатова // Baikal Research Journal. - 2017. - T. 8, № 4. - DOI : 10.17150/2411-6262.2017.8(4).29.

\section{For Citation}

Skorobogatova V. V. Recognition of a minor as being incompetent or partially incompetent: comparative-legal aspect. Baikal Research Journal, 2017, vol. 8, no. 4. DOI: 10.17150/24116262.2017.8(4).29. (In Russian).

\section{Baikal Research Journal}

